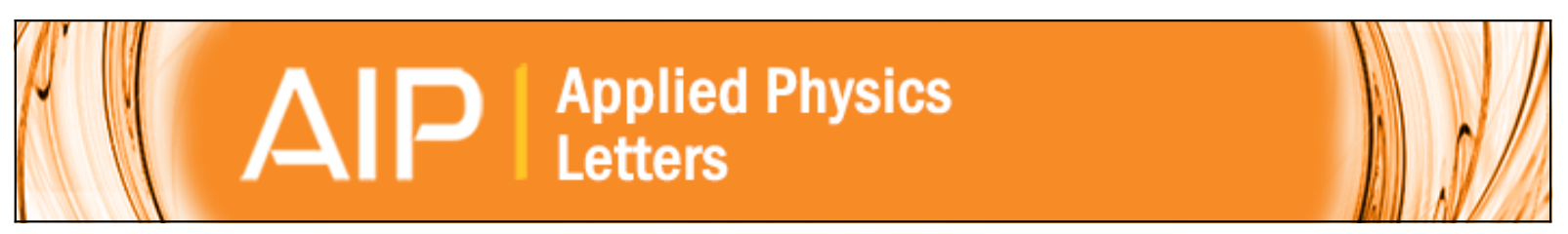

\title{
Viscosity measurements of metallic melts using the oscillating drop technique
}

P. Heintzmann, F. Yang, S. Schneider, G. Lohöfer, and A. Meyer

Citation: Applied Physics Letters 108, 241908 (2016); doi: 10.1063/1.4953871

View online: http://dx.doi.org/10.1063/1.4953871

View Table of Contents: http://scitation.aip.org/content/aip/journal/apl/108/24?ver=pdfcov

Published by the AIP Publishing

\section{Articles you may be interested in}

Wetting of bulk metallic glass forming liquids on metals and ceramics

J. Appl. Phys. 110, 043508 (2011); 10.1063/1.3615630

Noncontact measurement of high-temperature surface tension and viscosity of bulk metallic glass-forming alloys using the drop oscillation technique

Appl. Phys. Lett. 86, 014104 (2005); 10.1063/1.1844596

Syntactic bulk metallic glass foam

Appl. Phys. Lett. 84, 1108 (2004); 10.1063/1.1646467

Viscosity of eutectic Pd 78 Cu 6 Si 16 measured by the oscillating drop technique in microgravity

Appl. Phys. Lett. 73, 462 (1998); 10.1063/1.121900

Influence of oxygen on the viscosity of $\mathrm{Zr}-\mathrm{Al}-\mathrm{Cu}-\mathrm{Ni}$ metallic glasses in the undercooled liquid region J. Appl. Phys. 83, 3438 (1998); 10.1063/1.367114

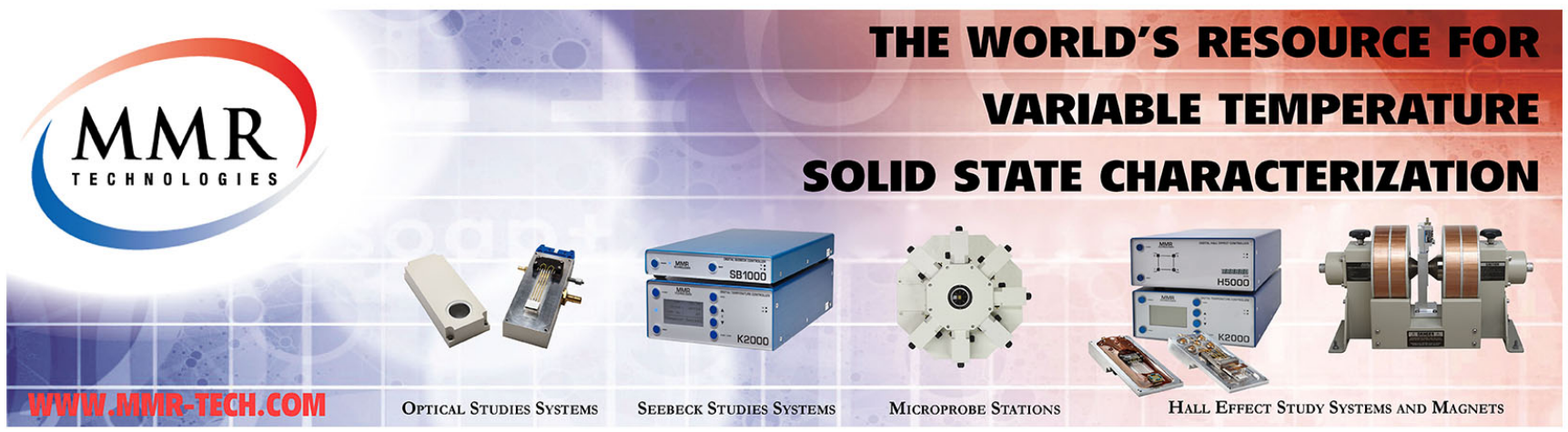




\title{
Viscosity measurements of metallic melts using the oscillating drop technique
}

\author{
P. Heintzmann, ${ }^{\text {a) }}$ F. Yang, S. Schneider, G. Lohöfer, and A. Meyer \\ Institut für Materialphysik im Weltraum, Deutsches Zentrum für Luft- und Raumfahrt (DLR), 51170 Köln, \\ Germany
}

(Received 23 March 2016; accepted 28 May 2016; published online 14 June 2016)

\begin{abstract}
By means of benchmarking reduced gravity experiments, we have verified the measured viscosity of binary $\mathrm{Zr}-\mathrm{Ni}$ glass forming liquids utilizing the oscillating drop technique combined with ground-based electrostatic levitation (ESL). Reliable viscosity data can be obtained as long as internal viscous damping of a single oscillation mode of a levitated drop dominates external perturbations. This can be verified by the absence of a sample mass dependence of the results. Hence, ESL is an excellent tool for studying the viscosity of metallic glass forming melts in the range of about 10-250 mPas, with sample masses below $100 \mathrm{mg}$. To this end, we show that, for binary Zr-Ni melts, the viscosity is qualitatively controlled by the packing density. Published by AIP Publishing. [http://dx.doi.org/10.1063/1.4953871]
\end{abstract}

Viscosity is an important melt property. On the microscopic scale, it represents the slow decay of stress fluctuations and reflects the collective mobility of the atoms. ${ }^{1}$ Hence, it plays an important role in solidification phenomena such as glass formation and crystallization. For macroscopic applications, it is an essential process parameter for, e.g., casting and thermoplastic forming. In the case of metallic glasses, viscosity is of particular interest, since it not only contributes to developing better glass formers but also to fabrication of nanostructures with extraordinary properties. ${ }^{2}$

Despite its importance, the determination of liquid viscosity, especially for metallic melts, is not a trivial task. Conventionally, this is done via shearing liquids in crucibles. The applicability of these techniques is limited mainly to chemically inert liquids. For metallic melts, these measurements become increasingly unreliable due to high melting temperatures and chemical reactivities of the melts, as reactions between the liquid and the container could alter the results.

One possibility to overcome these obstacles and handle such materials is the use of containerless processing techniques such as levitation. This also allows for investigations of supercooled liquids, which are an essential precursor to glass formation, since heterogeneous nucleation sites are absent. A technique to measure the viscosity on a levitated liquid droplet is the so called oscillating drop method (ODM). ${ }^{3,4}$ However, as shown in Fig. 1, for a bulk metallic glass (BMG) former $\mathrm{Zr}_{41.2} \mathrm{Ti}_{13.8} \mathrm{Cu}_{12.5} \mathrm{Ni}_{10} \mathrm{Be}_{22.5}$ (Vit1), the reported viscosity, ${ }^{5-7}$ using different techniques, exhibits large scattering up to an order of magnitude. Although the difference between container-based rotating cup and containerfree electrostatic levitation (ESL) methods can be interpreted as an effect of sample-crucible interactions, there is still a discrepancy of $\sim 30 \%-50 \%$ in the measured viscosity using the ESL technique.

The main reason for this deviation is that the viscosity derived from the ODM involves idealized assumptions and

${ }^{\text {a) Electronic mail: pascal.heintzmann@ } \mathrm{dlr} . d \mathrm{de}}$ is sensitive to experimental conditions. The aim of the present article is, hence, to investigate whether and under which experimental conditions the ODM provides reliable viscosity data, especially in combination with ESL, since it recently has been widely used ${ }^{7-10}$ and is probably the most advanced and suitable method for such measurements. ${ }^{11}$

In an ODM measurement, surface oscillations are first excited, then after switching off the excitation, the damping time $\tau$ of the oscillation amplitude is determined. An example is shown in Fig. 2. To obtain $\tau$, the time dependent oscillation amplitude is fitted by

$$
r(t)=r_{0}+A \times \sin (\omega t+\varphi) \exp \left(-\frac{t}{\tau}\right),
$$

with $r_{0}$ the radius of the unperturbed sample, $A$ the initial oscillating amplitude, $\omega$ the frequency of the oscillation, and $\varphi$ the phase shift. The mathematical basis for the relation between the oscillating drop and the viscosity has already been laid down by Rayleigh ${ }^{12}$ and Lamb. ${ }^{13}$ As a necessary prerequisite, it is assumed that the liquid droplet is perfectly

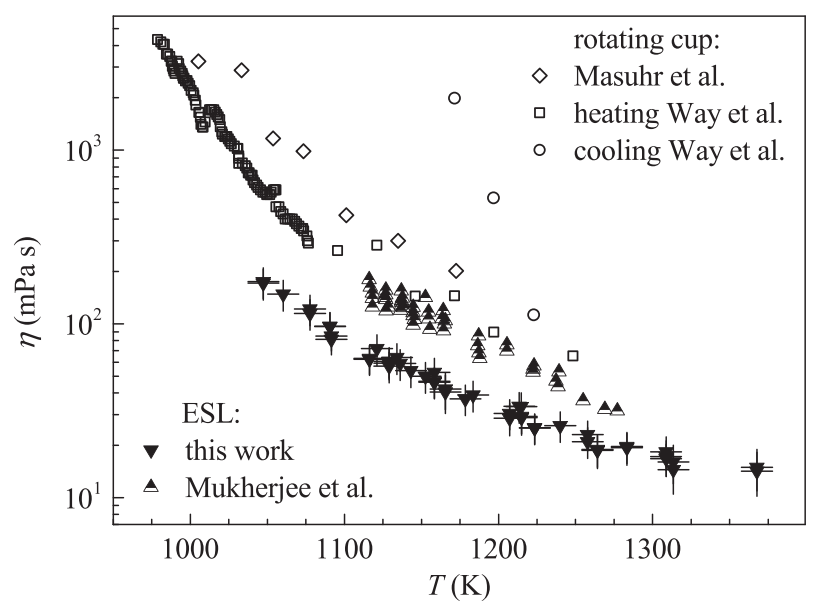

FIG. 1. Viscosity of liquid $\mathrm{Zr}_{41.2} \mathrm{Ti}_{13.8} \mathrm{Cu}_{12.5} \mathrm{Ni}_{10} \mathrm{Be}_{22.5}$ (Vit1) measured with different experimental techniques. ${ }^{5-7}$ Both container-based and container-free methods show discrepancies in the obtained melt viscosity. 


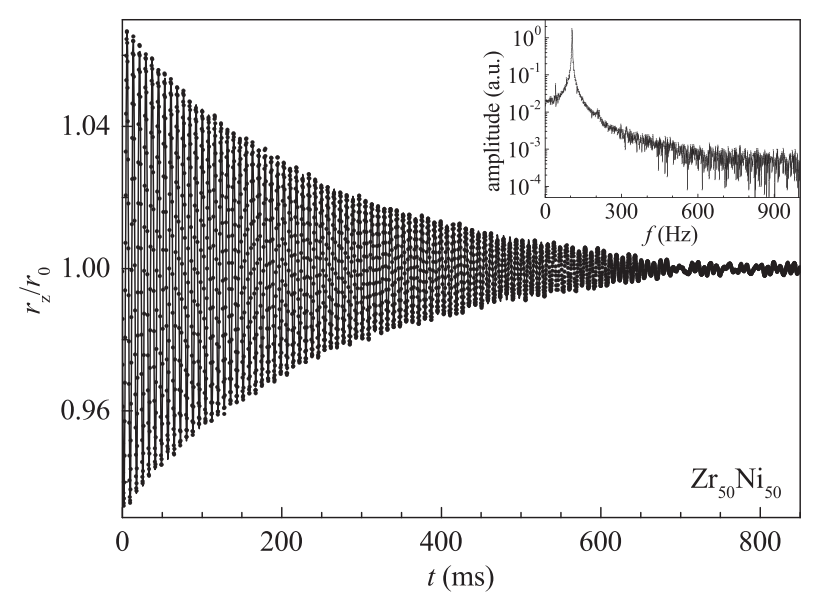

FIG. 2. Time dependent normalized radii (circles) of a liquid $\mathrm{Zr}_{50} \mathrm{Ni}_{50}$ sample, showing the decay of oscillations measured with ESL, together with a fit to the data (solid line). Inset: Frequency spectrum obtained from a Fourier transformation of the decay curve.

spherical, suspended force free, and the damping is solely due to internal friction in the liquid under laminar flow conditions. For commonly applied techniques to levitate metallic melts, such as ground-based electromagnetic levitation (EML) ${ }^{14,15}$ and ESL, ${ }^{16,17}$ these conditions are never fulfilled. The gravitational force is always present and the sample has to be levitated against this with a levitation force. In addition, there are levitation technique-specific limitations.

ESL utilizes electrostatic fields to levitate charged samples. Although the levitation field does not induce turbulence, such that internal flow can be considered as laminar, ${ }^{11}$ the presence of charge on the sample surface introduces additional forces on the sample. Furthermore, the sample position needs to be controlled actively, which may lead to additional disturbances during a measurement. In EML, forces are generated as a result of induced currents in electrically conducting samples. Accordingly, the samples are not electrically charged. However, in ground-based experiments, the EML field is so strong that surface deformations and turbulent flow are introduced, rendering viscosity measurements impossible. Only under reduced gravity ( $\mathrm{r}-\mathrm{g}$ ), where positioning fields are orders of magnitude smaller, the forcefree conditions can be regarded as being almost fulfilled. Therefore, we have performed benchmark experiments under $r$-g during parabolic flights in the TEMPUS ${ }^{18}$ EML facility to verify our ESL results.

We chose the binary $\mathrm{Zr}$-Ni glass forming alloy system complementing available viscosity, ${ }^{9}$ structure factor, ${ }^{19,20}$ and self-diffusion measurements, ${ }^{21,22}$ as well as mode coupling theory calculations ${ }^{23}$ and molecular dynamics simulations. ${ }^{24}$ As a base composition for several excellent $\mathrm{Zr}$-based BMGs, ${ }^{25,26}$ it has evolved as a model system for studying complex multicomponent glass forming melts, exhibiting very similar liquid dynamics to these BMGs. ${ }^{9,17,27}$ Moreover, the liquid density reported by Ohsaka et al. ${ }^{8}$ shows an extraordinary composition dependence, where the intermetallic composition $\mathrm{Zr}_{2} \mathrm{Ni}$ seems to have a particularly high density.

Sample mass $\left(m_{\mathrm{s}}\right)$ dependence was considered as a source of a systematic error of the oscillating drop technique. ${ }^{9,28,29}$ We therefore varied $m_{\mathrm{s}}$ over a factor of 10 from
$20 \mathrm{mg}$ up to $300 \mathrm{mg}$ in ESL, in order to analyze possible influences of the experimental setup (i.e., the electrostatic force) on the resulting viscosity. With the TEMPUS facility, $m_{\mathrm{s}}$ was further increased by another order of magnitude in comparison with the ESL measurements up to $\sim 1200 \mathrm{mg}$. All Zr-Ni samples were weighed out separately from pure $\mathrm{Zr}$ (99.97\%, smart-elements) and $\mathrm{Ni}(99.999 \%$, Alfa-Aesar) to the desired composition with a precision of $\leq 0.1$ at. $\%$. Subsequently, they were prepared by arc-melting under a Ti-gettered pure Ar (99.9999\%) atmosphere.

For the ESL measurements, we used two experimental setups: one for $m_{\mathrm{s}}=(20-90) \mathrm{mg}$ as described by Meister ${ }^{30}$ and one for $m_{\mathrm{s}}>90 \mathrm{mg}$ as described by Kordel et al. ${ }^{17}$ The main difference between the two setups is the maximum available levitation voltage. Samples were heated by two lasers in order to reduce sample temperature gradients. The sample temperature $T_{\mathrm{s}}$ was measured via single-color pyrometry and calibrated to the respective liquidus temperature $T_{l}$ reported in literature, ${ }^{31}$ assuming a temperature-independent liquid emissivity. The overall measurement uncertainty of $T_{\mathrm{s}}$ is about $\pm 10 \mathrm{~K}$, taking into account the uncertainty of the emissivity and of the liquidus temperature. The damping of the samples' oscillations after switching off the excitation was recorded with a high speed camera. A detailed description of the experimental setup is given in Ref. 9

Under the assumption of a force-free, spherical droplet the viscosity $\eta$ of the droplet can be derived according to ${ }^{13}$

$$
\eta=\frac{\rho r_{0}^{2}}{\tau_{1}(l-1)(2 l+1)},
$$

with $\rho$ the liquid density, $r_{0}$ the sample radius, $l$ the oscillation mode, and using $\tau$ determined by the fit from Eq. (1). In our experiments, only the $l=2$ oscillation mode was excited. This was verified by analyzing the Fourier transformed oscillation spectra, showing a single peak at the eigenfrequency of the sample, e.g., in the inset of Fig. 2 at around $\sim 105 \mathrm{~Hz}$.

Our TEMPUS experiments were conducted under a He atmosphere of $\leq 200$ mbar using a $1240 \mathrm{mg}$ sample. The impact of the medium on the viscosity measurement is negligibly small. Within a r-g time of $18-20 \mathrm{~s}$, the viscosity is measured in a similar way as described for the ESL facility, except that heating and positioning is realized with a coil system. ${ }^{32}$ The decay of the oscillation is recorded not only with a camera system (video) but also by a "Sample Coupling Electronics" (SCE) via a electromagnetic coupling mechanism. ${ }^{33,34}$ Viscosity was then derived as described above.

To calculate the melt viscosity using Eq. (2), the density of the melt is required as an input parameter. We hence measured the liquid density of all studied $\mathrm{Zr}-\mathrm{Ni}$ compositions in the above mentioned ESL setup ${ }^{30}$ with a shadow imaging technique. ${ }^{9,14}$ The volume of the sample was then calculated from the projected shadow area assuming an axial symmetry. Since the sample mass is known, density can be derived with an accuracy of $\Delta \rho / \rho \leq 0.01$. Fig. 3 shows our results for different $\mathrm{Zr}-\mathrm{Ni}$ compositions, compared with data from Ohsaka et al. ${ }^{8}$ In contrast to Ohsaka's results, where $\mathrm{Zr}_{2} \mathrm{Ni}$ exhibits a much higher density than the neighboring compositions, our measurements show a monotonic decrease of the liquid density with 


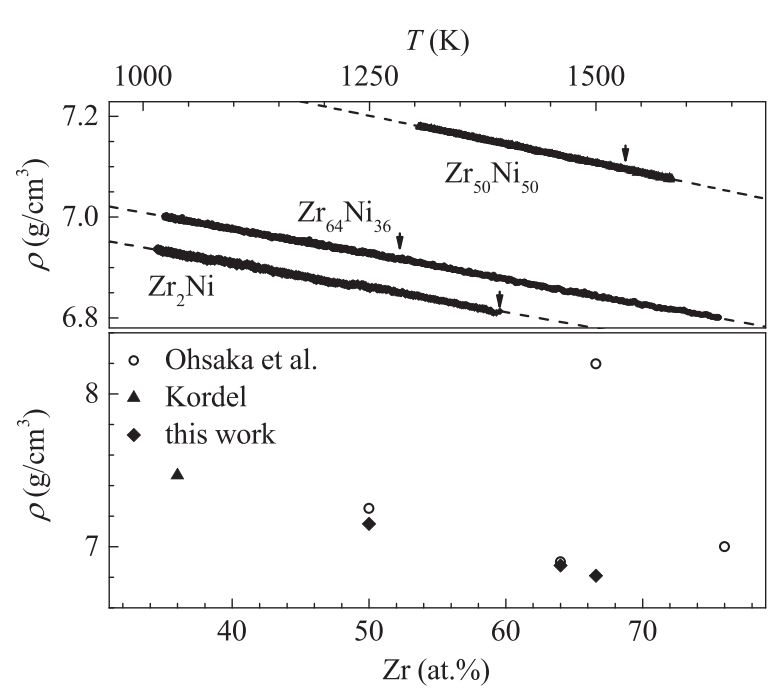

FIG. 3. Upper panel: Temperature dependent density of different alloys (as indicated in the graph) with linear fits to the data. Arrows mark the liquidus temperatures. Lower panel: Densities of $\mathrm{Zr}-\mathrm{Ni}$ alloys for different compositions measured with ESL at $1393 \mathrm{~K}$ together with results from Refs. 8 and 20 .

increasing $\mathrm{Zr}$ content in binary $\mathrm{Zr}$-Ni. The temperature dependence of the obtained density can be described by linear functions as $\rho(T)=\left(7.67-3.77 T \times 10^{-4}\right) \mathrm{g} \mathrm{cm}^{-3} \mathrm{~K}^{-1}$ for $\mathrm{Zr}_{50} \mathrm{Ni}_{50}$, $\rho(T)=\left(7.33-3.29 T \times 10^{-4}\right) \mathrm{g} \mathrm{cm}^{-3} \mathrm{~K}^{-1}$ for $\mathrm{Zr}_{64} \mathrm{Ni}_{36}$ and $\rho(T)=\left(7.26-3.21 T \times 10^{-4}\right) \mathrm{g} \mathrm{cm}^{-3} \mathrm{~K}^{-1}$ for $\mathrm{Zr}_{2} \mathrm{Ni}$.

The upper panel of Fig. 4 shows temperature dependent viscosity of $\mathrm{Zr}_{64} \mathrm{Ni}_{36}$ obtained by different levitation methods

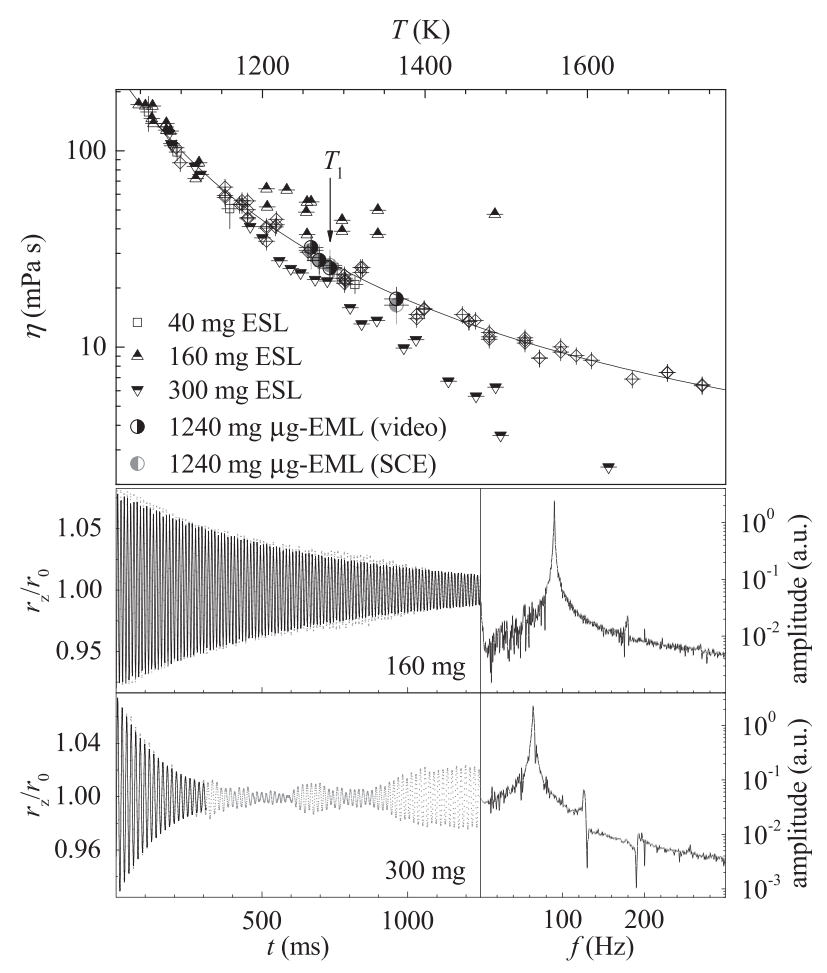

FIG. 4. Upper panel: Temperature dependent viscosity of $\mathrm{Zr}_{64} \mathrm{Ni}_{36}$ for different sample masses with a Vogel-Fulcher-Tammann fit. Open squares and half filled triangles show ESL measurements, half-filled circles are data obtained in the TEMPUS facility under r-g. Values from Ref. 9 with $m_{\mathrm{s}}=(20-86) \mathrm{mg}$ are plotted as open diamonds. Lower panel: Decay of sample oscillations (left column) using ESL at $\sim 1485 \mathrm{~K}$ ( $T$ of large viscosity deviations) with Fourier transformation (right column) of $\mathrm{Zr}_{64} \mathrm{Ni}_{36}$ samples. and different sample masses $m_{\mathrm{s}}$. Within the measurement uncertainties $(\Delta \eta=10 \%)$, our viscosity obtained using $m_{\mathrm{s}}=40 \mathrm{mg}$ exhibits the same temperature dependence as that of Brillo et al. ${ }^{9}$ This demonstrates the good reproducibility of these measurements. The results obtained under r-g agree with the described $1 \mathrm{~g}$ ESL data within error bars, independent of the data acquisition method (video analysis $\Delta \eta=15 \%$ and SCE $\Delta \eta=20 \%$ ). Viscosity data obtained in ESL using higher sample masses deviate from the described results (see Fig. 4). For $m_{\mathrm{s}}=160 \mathrm{mg}$, the viscosity is lower compared to that obtained from smaller samples at $T \gtrsim 1280 \mathrm{~K}$. Disagreements can also be found between the data obtained from $m_{\mathrm{s}}=300 \mathrm{mg}$ and from $m_{\mathrm{s}}=20-86 \mathrm{mg}$. However, the results of the $300 \mathrm{mg}$ sample exhibit larger values than that of the smaller samples at $T \gtrsim 1200 \mathrm{~K}$. In both cases, the deviation increases with increasing $T$, whereas above $\eta \approx 80 \mathrm{mPas}$ and below $T \approx 1120 \mathrm{~K}$ all viscosity measurements show good agreement.

To understand the differing behavior of the viscosity curves for high $m_{\mathrm{s}}(\geq 160 \mathrm{mg})$ at high $T(\geq 1200 \mathrm{~K})$, it is vital to analyze the decay curves of the oscillating amplitude. In the case of an undisturbed decay, a single frequency in the Fourier transformed spectrum is observed. For the $m_{\mathrm{s}}=160 \mathrm{mg}$ sample, a superposition of the main oscillation frequency (approx. $90 \mathrm{~Hz}$ ) with a further oscillation of low frequency is visible in the decay curve between $450 \mathrm{~ms}$ and $1000 \mathrm{~ms}$, as shown in Fig. 4. This additional oscillation is also noticeable in the Fourier transform at low frequencies of a few $\mathrm{Hz}(0-5 \mathrm{~Hz})$. An explanation for this is a periodic perturbation during the decay of the oscillation, possibly due to the vibration of the levitation facility and/or the sample, which introduced additional excitations during the decay. This leads to a larger decay constant $\tau$, and hence, to an underestimation of the viscosity. For even higher sample masses $\left(m_{\mathrm{s}}=300 \mathrm{mg}\right)$, more pronounced beats can be observed in the oscillation amplitudes, leading to a splitting of the oscillation frequency (approx. $64 \mathrm{~Hz}$ ). Typically, this indicates additional oscillation modes caused by, e.g., sample rotation. Hence, the damping of the oscillation amplitude cannot be attributed to a single oscillation mode, which explains a faster decay and an overestimation of the viscosity.

For viscosity values obtained under conditions of a single damping mode without external perturbation, no sample mass dependence can be observed for the range below $100 \mathrm{mg}$ for ESL and more than $1200 \mathrm{mg}$ in the TEMPUS facility, i.e., more than an order of magnitude. For small samples levitated in ESL, the positioning forces against perturbation, especially along the direction of gravity, are sufficiently small compared to the sample surface tension, so that no additional oscillation is induced. Hence, it can be assumed that, as long as the damping of a single oscillation mode dominates external perturbations, the measurements are not prone to the experimental conditions, and reliable viscosity data can be obtained. This is further confirmed by the fact that for a liquid viscosity higher than $80 \mathrm{mPas}$ all measurement results converge and by the good agreement on the viscosity of $\mathrm{Zr}_{50} \mathrm{Ni}_{50}$ between our data and those from Ref. 8. On the other hand, the comparable temperature dependence of Ohsaka's $\mathrm{Zr}_{64} \mathrm{Ni}_{36}$ data to 


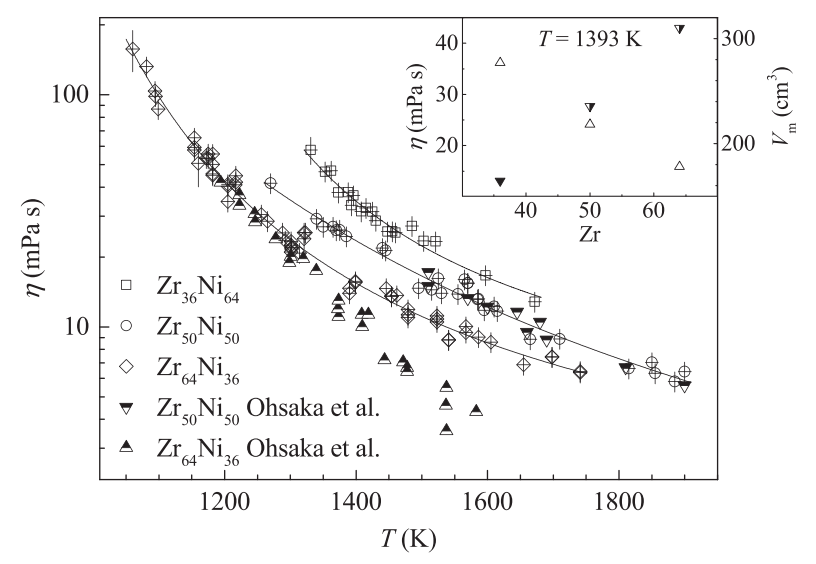

FIG. 5. Temperature dependent viscosity of $\mathrm{Zr}-\mathrm{Ni}$ alloys for different compositions. Data are measured with ESL and are fitted with a VFT fit (solid lines). An inset shows a comparison of concentration dependent viscosity (open triangles) at $1393 \mathrm{~K}$ together with calculated molar volumes (halffilled triangles) from our density measurements and one value from Ref. 20 (filled triangle).

our results of the $160 \mathrm{mg}$ sample indicates possible measurement disturbances in the low viscosity ( $\$ 10 \mathrm{mPa} \mathrm{s}$ ) regime.

Based on the verification of the viscosity measurements in ESL by r-g experiments, we further investigated the composition dependence of the viscosity of the binary $\mathrm{Zr}-\mathrm{Ni}$ system. Fig. 5 shows the viscosity data for $\mathrm{Zr}_{36} \mathrm{Ni}_{64}, \mathrm{Zr}_{50} \mathrm{Ni}_{50}$ and $\mathrm{Zr}_{64} \mathrm{Ni}_{36}$ obtained using ESL. The temperature dependence of the viscosity can well be described by a VFT equation,

$$
\eta=\eta_{0} \times \exp \left(\frac{E_{\eta}}{k_{\mathrm{B}}\left(T-T_{0}\right)}\right)
$$

for all three compositions. For the $\mathrm{Zr}_{64} \mathrm{Ni}_{36}$ melt, this yields $E_{\eta}=(3.4 \pm 0.8) \times 10^{-20} \mathrm{~J}, T_{0}=(599 \pm 70) \mathrm{K}$, and $\eta_{0}=(0.74 \pm 0.37) \mathrm{mPa}$. The other two investigated compositions can be described by $E_{\eta}=(4.3 \pm 0.2) \times 10^{-20} \mathrm{~J}$, $T_{0}=(501 \pm 38) \mathrm{K}$ for $\mathrm{Zr}_{50} \mathrm{Ni}_{50}$ and $E_{\eta}=(3.7 \pm 0.8) \times 10^{-20}$ $\mathrm{J}, T_{0}=(708 \pm 70) \mathrm{K}$ for $\mathrm{Zr}_{36} \mathrm{Ni}_{64}$. Here $\eta_{0}=(0.74) \mathrm{mPa} \mathrm{s}$ is kept as a constant for $\mathrm{Zr}_{50} \mathrm{Ni}_{50}$ and $\mathrm{Zr}_{36} \mathrm{Ni}_{64}$ for the fit, since viscosity was measured at much higher temperatures. At fixed temperature, the viscosity increases with decreasing $\mathrm{Zr}$ content, changing from $\mathrm{Zr}_{64} \mathrm{Ni}_{36}$ to $\mathrm{Zr}_{50} \mathrm{Ni}_{50}$ and from $\mathrm{Zr}_{50} \mathrm{Ni}_{50}$ to $\mathrm{Zr}_{36} \mathrm{Ni}_{64}$ by a factor $\sim 1.3$ and $\sim 1.6$, respectively. This behavior can be understood by an increase of the molar volume (see Fig. 5 inset) and hence a decrease of the packing fraction of the melt. Note that for the packing fraction, derived from the macroscopic density of the melt, a statistical random distribution of atoms is assumed, while $\mathrm{Zr}-\mathrm{Ni}$ melts are known to exhibit pronounced chemical short range order. ${ }^{19,20}$ However, unlike the ternary $\mathrm{Zr}$-(Co,Ni)-Al melts, ${ }^{35}$ here an average molar volume (packing fraction) can still capture the composition dependence of the liquid viscosity qualitatively.

In conclusion, we have measured the viscosity of the binary $\mathrm{Zr}-\mathrm{Ni}$ system by oscillating drop techniques, using both ESL and the TEMPUS EML reduced gravity ( $r-g$ ) facility. Our findings show that reliable viscosity data can only be obtained when a single oscillation mode dominates viscous damping. For ground based ESL, these conditions can be found for sample masses below $100 \mathrm{mg}$ and a viscosity range of 10-250 $\mathrm{mPa}$ s. Using EML under r-g conditions, the same holds for masses up to $\sim 1 \mathrm{~g}$. Besides the rare r-g opportunities, ESL enables systematic studies of the viscosity of chemically reactive metallic glass forming melts, which typically lies in the range of tens to hundreds of $\mathrm{mPa}$, at temperatures from above their liquidus down to the undercooled regime. We have shown that for the binary $\mathrm{Zr}-\mathrm{Ni}$ system atomic packing qualitatively controls the viscosity. Combined with low temperature viscosity data, this allows to investigate the kinetic contribution to the glass formation ${ }^{35}$ and related interesting phenomena, such as strong-fragile transitions. ${ }^{6}$

We would like to thank the German Space Agency, Bonn, which enabled us to take part in the parabolic flight mission, and the members of the TEMPUS team for operating the TEMPUS facility. The financial support provided by the Deutsche Forschungsgemeinschaft (DFG) through the grant (No. ME 1958/10-1) is gratefully acknowledged.

${ }^{1}$ T. Iida and R. I. L. Guthrie, The Physical Properties of Liquid Metals (Oxford University Press, 1988).

${ }^{2}$ J. Schroers, Phys. Today 66(2), 32 (2013).

${ }^{3}$ I. Egry, G. Lohöfer, I. Seyhan, S. Schneider, and B. Feuerbacher, Appl. Phys. Lett. 73, 462 (1998).

${ }^{4}$ I. Egry, H. Giffard, and S. Schneider, Meas. Sci. Technol. 16, 426 (2005).

${ }^{5}$ A. Masuhr, T. A. Waniuk, R. Busch, and W. L. Johnson, Phys. Rev. Lett. 82, 2290 (1999).

${ }^{6}$ C. Way, P. Wadhwa, and R. Busch, Acta Mater. 55, 2977 (2007).

${ }^{7}$ S. Mukherjee, J. Schroers, Z. Zhou, W. Johnson, and W.-K. Rhim, Acta Mater. 52, 3689 (2004).

${ }^{8}$ K. Ohsaka, S. K. Chung, and W. K. Rhim, Acta Mater. 46, 4535 (1998).

${ }^{9}$ J. Brillo, A. Pommrich, and A. Meyer, Phys. Rev. Lett. 107, 165902 (2011).

${ }^{10}$ N. A. Mauro, M. Blodgett, M. L. Johnson, A. J. Vogt, and K. F. Kelton, Nat. Commun. 5, 4616 (2014).

${ }^{11}$ R. W. Hyers, Meas. Sci. Technol. 16, 394 (2005).

${ }^{12}$ L. Rayleigh, Proc. R. Soc. London 29, 71 (1879).

${ }^{13}$ H. Lamb, Proc. London Math. Soc. 1-13, 51 (1881).

${ }^{14}$ J. Brillo and I. Egry, Int. J. Thermophys. 24, 1155 (2003).

${ }^{15}$ D. Holland-Moritz, T. Schenk, P. Convert, T. Hansen, and D. M. Herlach, Meas. Sci. Technol. 16, 372 (2005).

${ }^{16}$ W.-K. Rhim, S. K. Chung, D. Barber, K. F. Man, G. Gutt, A. Rulison, and R. E. Spjut, Rev. Sci. Instrum. 64, 2961 (1993).

${ }^{17}$ T. Kordel, D. Holland-Moritz, F. Yang, J. Peters, T. Unruh, T. Hansen, and A. Meyer, Phys. Rev. B 83, 104205 (2011).

${ }^{18}$ T. Tempus, "Materials and fluids under low gravity," in Containerless Processing in Space: Recent Results, Lecture Notes in Physics Vol. 464 (Springer, Berlin, Heidelberg, 1995), pp. 233-252.

${ }^{19}$ D. Holland-Moritz, S. Stüber, H. Hartmann, T. Unruh, T. Hansen, and A. Meyer, Phys. Rev. B 79, 064204 (2009).

${ }^{20}$ T. Kordel, Ph.D. thesis, Ruhr-Universität Bochum, 2011.

${ }^{21}$ D. Holland-Moritz, S. Stüber, H. Hartmann, T. Unruh, and A. Meyer, J. Phys.: Conf. Ser. 144, 012119 (2009).

${ }^{22}$ S. W. Basuki, E. Gill, K. Rätzke, F. Yang, A. Meyer, and F. Faupel, "Atomic dynamics in Zr-based glass forming alloys near the liquidus temperature" (to be published).

${ }^{23}$ T. Voigtmann, A. Meyer, D. Holland-Moritz, S. Stüber, T. Hansen, and T. Unruh, Europhys. Lett. 82, 66001 (2008).

${ }^{24}$ P. Kuhn, J. Horbach, F. Kargl, A. Meyer, and T. Voigtmann, Phys. Rev. B 90, 024309 (2014).

${ }^{25}$ A. Peker and W. L. Johnson, Appl. Phys. Lett. 63, 2342 (1993).

${ }^{26}$ X. H. Lin and W. L. Johnson, J. Appl. Phys. 78, 6514 (1995).

${ }^{27}$ F. Yang, T. Unruh, and A. Meyer, Europhys. Lett. 107, 26001 (2014).

${ }^{28}$ T. Ishikawa, P.-F. Paradis, N. Koike, and Y. Watanabe, Rev. Sci. Instrum. 80, 013906 (2009).

${ }^{29}$ A. I. Pommrich, Ph.D. thesis, Ruhr-Universität Bochum, 2010.

${ }^{30}$ T. Meister, Ph.D. thesis, Ruhr-Universität Bochum, 2000. 
${ }^{31}$ T. B. Massalski, Binary Alloy Phase Diagrams (ASM International, Ohio, 1990).

${ }^{32}$ G. Lohöfer and G. Pottlacher, High Temp. - High Pressures 40, 237 (2011), http://www.oldcitypublishing.com/HTHP/HTHPcontents/HTHP40.34contents.html.

${ }^{33} \mathrm{R}$. Willnecker, S. Schneider, and F. Munstermann, in 56th International Astronautical Congress of the International Astronautical Federation, the
International Academy of Astronautics, and the International Institute of Space Law (American Institute of Aeronautics and Astronautics, Reston, Virginia, 2005), pp. 1-7.

${ }^{34} \mathrm{G}$. Lohöfer and J. Piller, in Proceedings of the 40th AIAA Aerospace Sciences Meeting and Exhibit (Reno, USA, 2002).

${ }^{35}$ C. C. Yuan, F. Yang, F. Kargl, D. Holland-Moritz, G. G. Simeoni, and A. Meyer, Phys. Rev. B 91, 214203 (2015). 